\title{
Combined external quality assessment of cytology and histology opinions: a pilot scheme for a cluster of five laboratories
}

\author{
OAN HUSAIN, ${ }^{*}$ E BLANCHE BUTLER, $\dagger$ FP WOODFORD $\ddagger$
}

\author{
From the *Regional Cytology Centre, St Stephen's Hospital, Chelsea, London SW10 9TH; the †Cytology \\ Laboratory, St Mary's Hospital, Hathaway Road, Manchester M13 0JM; and the $\ddagger$ Department of Health and \\ Social Security, Hannibal House, London SE1 6TE
}

SUMMARY A cluster of five self selected cytodiagnostic laboratories circulated 70 cervical/vaginal smears and 50 sputum smears in a series of five week cycles. Histological sections related to the abnormal smears were also circulated. Proportions of agreement and disagreement were analysed for cervical and sputum smear reports against the original report (and by implication against the consensus); corresponding calculations were made for the histological reports. Cytological and histological correlation was also examined.

Agreement for major categories (benign, intraepithelial neoplasia, malignant) was $87 \%$ for cervical cytology and $83 \%$ for sputum. When the effect of potential random agreement was compensated for by the use of kappa statistics the values of kappa were +0.79 and +0.65 , respectively. The corresponding kappa values for gynaecological and respiratory tract histology were +0.78 and $+\mathbf{0 . 8 2}$, respectively. Agreement on finer degrees of abnormality was, predictably, less good.

Problems arising in this pilot scheme are discussed and suggestions for a simplified scheme are made.

To devise an external quality assessment system for cytology analogous to those in other pathology disciplines such as clinical chemistry or haematology is not easy. ${ }^{2}$ The main problem is not, as is often asserted, the difficulty of comparing qualitative as opposed to quantitative results because this also applies in microbiology, where the problem has been solved. ${ }^{3}$ Nor is it the problem of comparing interpretive opinions where there is no absolute standard of correctness; kappa statistics can be applied to analyse interobserver variation in pattern recognition ${ }^{4}$ and these have been applied satisfactorily in histological observer studies. ${ }^{67}$ The unique difficulty in cytopathology is that it is not possible to produce identical clinical specimens for simultaneous examination by different laboratories.

The only solution to this problem is to circulate

Accepted for publication 8 May 1984

The views expressed in this paper are those of the authors and do not necessarily reflect Department of Health and Social Security policy with respect to external quality assessment in cytology. single smears around a small cluster of laboratories; this method has been used with success by Evans $e t$ al. ${ }^{8}$ Material can be provided by a single centre, but it spreads the burden if all participants contribute. The most important variation in design is the decision on the reference point ("correct result") to be used. This can be one of the following:

1 Cytological: $(a)$ the originating laboratory's opinion; $(b)$ the opinion of a single external assessor; $(c)$ consensus of the cluster; $(d)$ consensus tempered by referral to an external "expert."

2 Histological: the histological report on relevant tissue corresponding to the test smear.

The histological alternative has three inherent difficulties: smears originally classified as "negative" will be unlikely to have a corresponding histological report; biopsy may be inadequate because of size or failure to sample the correct site; and there is well documented evidence of disagreement among histopathologists on the interpretation of a given microscopical appearance. ${ }^{9}$

We have attempted to address these problems by linking (for the first time, to our knowledge) a cluster of cytology laboratories with their corresponding 
histology laboratories in an opinion comparison exercise entailing the circulation of cervical/vaginal and respiratory tract smears and the corresponding histological sections over a period of about one year.

\section{Material and methods}

The five cytology laboratories which participated each provided 20 smears for the whole study. Ten of these were cervical/vaginal smears and 10 were sputum. Smears were circulated in five cycles, each lasting five weeks. The order of circulation was prearranged, and in the first week of the cycle all laboratories originated four smears and sent them to the next one in the cluster; one week was allowed for the receiving laboratory to report before sending the material to the next in order. In this way material was returned to the originating laboratory in the fifth week, and 80 new reports were generated in the cycle (to be compared with 20 reports from the originating laboratories). An interval of one week was allowed between cycles to compensate for any delays in circulation.

A reporting proforma was designed in five sections, which consisted of:

1 Assessment of the quality of material from the point of view of adequacy of the specimen, quality of fixation, and quality of staining.

2 Identification of inflammatory changes and the presence of any specific cause of infection.

3 Identification of the types of cells present-that is, normal, reactive, dyskaryotic or suggestive of an invasive lesion These were further subdivided according to the type and degree of differentiation.

4 Prediction of the histological abnormality (if any).

5 Recommendations for future patient management.

These forms were completed by the originating laboratory and all receiving laboratories for each smear and sent to the coordinating laboratory.

No attempt was made to introduce specimens "blind" as they could each be identified as foreign to the receiving laboratory. On average, half of the total material provided by each laboratory was negative; this included smears showing reactive changes due to infection or healing. The remainder of the smears contained seriously abnormal or obviously malignant cells.

As part of the second and all subsequent cycles, histological sections corresponding to smears from the previous cycle were circulated; these were to be reported by histopathologists in each receiving laboratory. The mechanism for circulation of sections was the same as that for cytological material and was also the responsibility of the cytopatholog- ist. A sixth cycle was added, partly to increase the number of reports available for analysis and partly to evaluate a modification of the circulation process. A disadvantage of the scheme as described above was the delay before the original cytology and histology reports were available to receiving laboratories. It was also not possible to review cytological material in the light of these reports or to compare smears with relevant sections. For the sixth cycle, cervical/vaginal material only was circulated, and the sets of four test smears were accompanied by a sealed envelope containing original reports with related histological sections and their reports. This envelope was opened after the receiving laboratory reports were completed; the test smears could be re-examined in the light of its contents before being forwarded with the resealed evelope to the next in the cluster. Histopathologists did not take part in this cycle.

\section{Results}

At the end of the study 70 cervical/vaginal smears and 50 sputum smears had been circulated; thus 280 and 200 reports from receiving laboratories should have been available for analysis. In the same way 28 sections of gynaecological tract tissue and $25 \mathrm{sec}-$ tions of respiratory tract material had been circulated, with a possibility of 112 and 100 reports, respectively. For analysis of cytological and histological correlation the cytology reports given by the originating laboratory were included so that for gynaecological material there was a possibility of 140 cytology reports related to the 28 sections circulated and in the case of respiratory tract material there was a possibility of 130 cytology reports to correlate with 25 sections. The additional cytology reports resulted from one laboratory's circulation of two sputum specimens from the same case.

For various reasons maximum numbers of reports were not achieved and the final analysis was carried out on:

Cervical/vaginal smears-251 reports against 70 original reports

Sputum smears -181 reports against 50 original reports

Gynaecological sections -100 reports against 28 original reports

Respiratory tract sections -90 reports against 25 original reports

Gynaecological histology and cytology correlations -132 cytology reports related to $28 \mathrm{sec}$ tions

Respiratory histology and cytology correlation124 cytology reports related to 25 sections.

Many of the returned proformas were incomplete: 
the only information always given was the observation of the most abnormal type of cell present and a prediction of the most severe histological abnormality. Consequently, cytological and histological reports were analysed in two ways. In the first, major categories of agreement and disagreement, defined as those which would affect clinical management, were identified for cervical/vaginal smears (Table 1a). These were:

$\mathrm{B}=$ negative smears predicting no abnormality or a benign lesion-that is, reactive changes or specific infection

IN = smears containing dyskaryotic cells predicting no more than intraepithelial neoplasia. This was usually cervical (CIN) and occasionally vaginal (VAIN)

$\mathbf{M}=$ smears containing malignant cells or cells suspicious of malignancy, predicting a high probability of invasive cancer.

In the case of sputum smears (Table 1b) categories $B$ and $M$ only were used.

Reports on gynaecological and respiratory tract sections were analysed under the same categories (Tables $2 a$ and $b$ ), but here the reports took the form of a definite statement rather than a prediction.

Correlation of cervical smear reports with original reports on sections of gynaecological tissue followed the same format, but again in the correlation of sputum smear reports with respiratory tract tissue categories $B$ and $\mathbf{M}$ only were used (Tables $3 a$ and b). Because there was no greater discrepancy when cytology reports were compared with histology reports made in their own laboratories (not shown) it seemed reasonable to include original cytology reports in this table.

The second analysis looked at proportions of agreement and disagreement in degree or type of malignancy where there was agreement as to the stage of neoplasia. Tables $4 \mathrm{a}$ and $\mathrm{b}$ show this for cervical smears and sputum (degree of intraepithelial neoplasia and cancer type for cervical smears, but tumour type only for sputum). Tables $5 \mathrm{a}$ and $\mathrm{b}$ follow the same format for comparison of histological reports on tissue sections and Tables $6 a$ and $b$ for the cytological and histological correlation. Table $6 \mathrm{a}$, which deals with the correlation of gynaecological smears and tissue, differs in that areas of disagreement between intraepithelial neoplasia and invasive cancer are also expressed.

Numbers were often too small for statistical evaluation of the performance of individual laboratories to be valid. Tables 1 and 4 analyse the performance of the whole group with regard to cytology reports with kappa statistics appended, while Tables 7 and 8 list the kappa statistics for individual laboratories without the raw data. For comparison of histological section reports (Tables 2 and 5) and cytological and histological correlation (Tables 3 and 6) the performance of the whole group is analysed; figures for individual laboratories are not presented.

The application of kappa statistics in comparing interpretive opinions has been mentioned elsewhere,$^{4-7}$ and these were applied with particular reference to recent reports by Thomas $e t a^{10}$ and Silcocks." Kappa $(\kappa)$ is a measure of agreement between observers which takes account of the possibility of chance agreement; simple calculations of percentage agreements do not take account of these effects. The disadvantages of kappa are that it requires a fairly large sample size and that major disagreement over a particular category may only minimally affect kappa when the number of cases in a particular category of an $\mathbf{n} \times \mathbf{n}$ table is small in comparison with other categories. " The latter problem is apparent in Tables 2 and 3 and is due to the

Table 1 Cytology: all receiving laboratory reports compared with original reports. Major categories.

\begin{tabular}{|c|c|c|c|c|c|}
\hline \multirow[t]{2}{*}{ (a) Cervical smears } & & \multicolumn{4}{|c|}{ All receiving laboratories } \\
\hline & & $B$ & IN & $M$ & Total \\
\hline $\begin{array}{l}\text { Originating laboratory's opinion } \\
\mathrm{P}_{\mathrm{o}}=0.87, \mathrm{P}_{\mathrm{e}}=0 \cdot 37, \kappa=+0 \cdot 7\end{array}$ & $\begin{array}{l}\text { B } \\
\text { IN } \\
\text { M } \\
\text { Total } \\
\kappa=0\end{array}$ & $\begin{array}{r}89 \\
1 \\
3 \\
93 \\
\text { fider }\end{array}$ & $\begin{array}{r}1 \\
31 \\
9 \\
41 \\
76\end{array}$ & $\begin{array}{r}4 \\
14 \\
99 \\
117 \\
03, F\end{array}$ & $\begin{array}{r}94 \\
46 \\
111 \\
251\end{array}$ \\
\hline
\end{tabular}

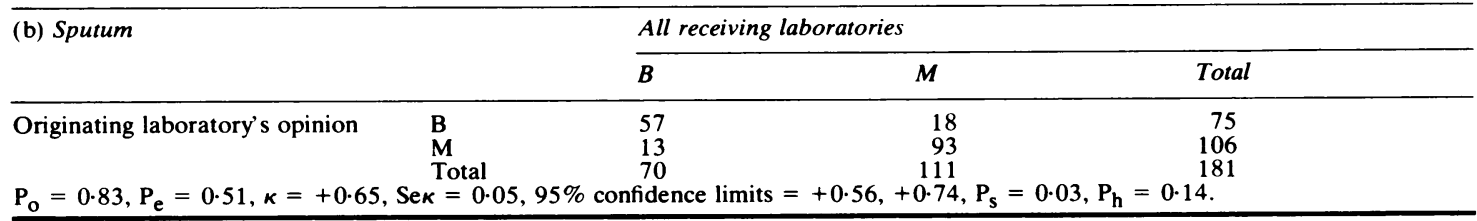

$P_{0}$, observed proportion of agreement; $P_{e}$, expected proportion of agreement; $\kappa$, kappa; Se $\kappa$, standard error of kappa; $P_{s}$, systemic disagreement; $\mathrm{P}_{\mathrm{h}}$, haphazard disagreements; $\mathrm{B}$, benign; IN, intraepithelial neoplasia; $\mathrm{M}$, probable invasive cancer. 
Table 2 Histology: all receiving laboratory reports compared with originating laboratory opinions. Major categories.

\begin{tabular}{|c|c|c|c|c|c|}
\hline \multirow[t]{2}{*}{ (a) Gynaecological tissue } & & \multicolumn{4}{|c|}{ All receiving laboratories } \\
\hline & & $B$ & $I N$ & $M^{*}$ & Total \\
\hline Originating laboratory's opinion & $\begin{array}{l}\text { B } \\
\text { IN } \\
\text { M } \\
\text { Total }\end{array}$ & $\begin{array}{l}1 \\
0 \\
1 \\
2\end{array}$ & $\begin{array}{r}0 \\
27 \\
1 \\
28\end{array}$ & $\begin{array}{r}0 \\
8 \\
62 \\
70\end{array}$ & $\begin{array}{r}1 \\
35 \\
64 \\
100\end{array}$ \\
\hline
\end{tabular}

\begin{tabular}{|c|c|c|c|c|c|}
\hline \multirow[t]{2}{*}{ (b) Respiratory tract tissue } & & \multicolumn{4}{|c|}{ All receiving laboratories } \\
\hline & & $B$ & $I N$ & $M$ & Total \\
\hline Originating laboratory's opinion & $\begin{array}{l}\text { B } \\
\text { IN } \\
\text { M } \\
\text { Total }\end{array}$ & $\begin{array}{l}4 \\
0 \\
0 \\
4\end{array}$ & $\begin{array}{l}0 \\
0 \\
2 \\
2\end{array}$ & $\begin{array}{r}0 \\
0 \\
84 \\
84\end{array}$ & $\begin{array}{r}4 \\
0 \\
86 \\
90\end{array}$ \\
\hline
\end{tabular}

${ }^{*}$ Includes cases reported as suspicious of microinvasion.

For abbreviations see Table 1 .

Table 3 Correlation between histology and cytology: all cytology reports (originating and receiving laboratories) compared with original histology reports. Major categories.

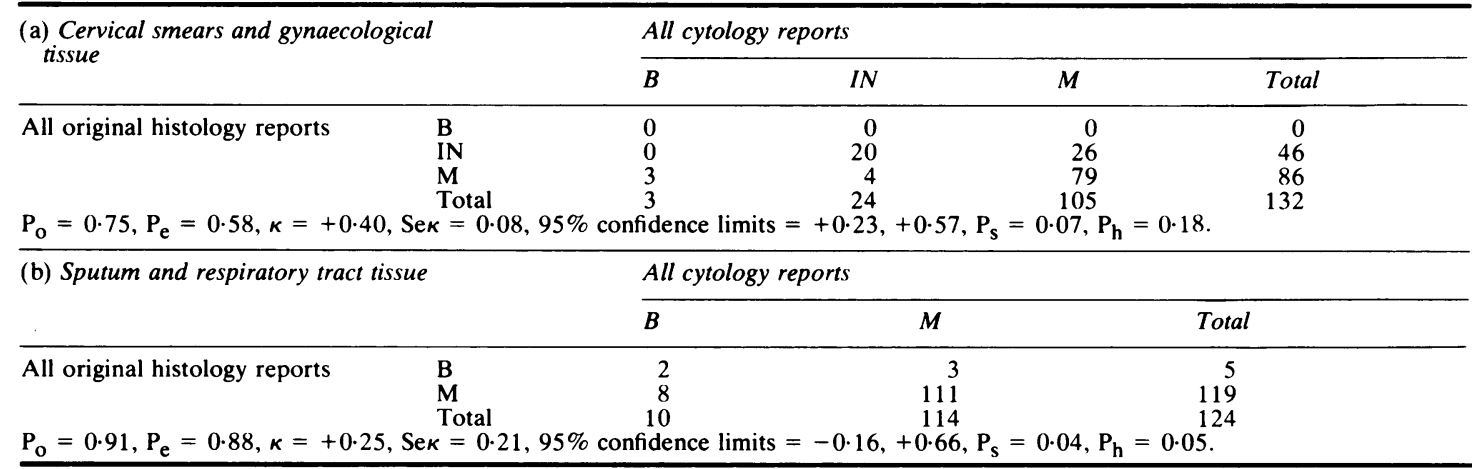

For abbreviations see Table 1 .

Table 4 Cytology: all receiving laboratory reports compared with original reports. Degree of intraepithelial neoplasia and type of invasive tumour.

\begin{tabular}{|c|c|c|c|c|c|c|c|}
\hline \multirow[t]{2}{*}{ (a) Cervical smears } & & \multicolumn{6}{|c|}{ All receiving laboratories } \\
\hline & & $I N I, I I$ & IN III & $S q$ & Ad & Other & Total \\
\hline Originating laboratory's opinion & $\begin{array}{l}\text { IN I, II } \\
\text { IN III } \\
\text { Sq } \\
\text { Ad } \\
\text { Other } \\
\text { Total }\end{array}$ & $\begin{array}{r}8 \\
2 \\
0 \\
0 \\
0 \\
10\end{array}$ & $\begin{array}{r}5 \\
16 \\
0 \\
0 \\
0 \\
21\end{array}$ & $\begin{array}{r}0 \\
0 \\
35 \\
2 \\
0 \\
37\end{array}$ & $\begin{array}{r}0 \\
0 \\
4 \\
43 \\
5 \\
52\end{array}$ & $\begin{array}{r}0 \\
0 \\
3 \\
4 \\
3 \\
10\end{array}$ & $\begin{array}{r}13 \\
18 \\
42 \\
49 \\
8 \\
130\end{array}$ \\
\hline
\end{tabular}

\begin{tabular}{|c|c|c|c|c|c|c|}
\hline \multirow[t]{2}{*}{ (b) Sputum } & & \multicolumn{5}{|c|}{ All receiving laboratories } \\
\hline & & $S q$ & Ad & Oat & Other & Total \\
\hline$P_{o}=0.72, P_{e}=0.30, \kappa=+0.6$ & $\begin{array}{l}\text { Sq } \\
\text { Ad } \\
\text { Oat } \\
\text { Other } \\
\text { Total } \\
\kappa=0.0\end{array}$ & $\begin{array}{r}34 \\
3 \\
1 \\
3 \\
41 \\
\text { fide }\end{array}$ & $\begin{array}{c}3 \\
11 \\
0 \\
0 \\
14 \\
+0\end{array}$ & $\begin{array}{r}0 \\
3 \\
13 \\
1 \\
17 \\
P_{s}=\end{array}$ & $\begin{array}{r}5 \\
4 \\
3 \\
9 \\
21 \\
=0 \cdot 19 .\end{array}$ & $\begin{array}{l}42 \\
21 \\
17 \\
13 \\
93\end{array}$ \\
\hline
\end{tabular}

IN I, II intraepithelial neoplasia I and II; IN III intraepithelial neoplasia III; Sq, squamous cell carcinoma; Ad, adenocarcinoma; Oat, oat cell carcinoma (small cell undifferentiated); Other, differentiation uncertain or other invasive tumour. For other abbreviations see Table 1. 
Combined external quality assessment of cytology and histology opinions

Table 5 Histology: all receiving laboratory reports compared with originating laboratory reports. Degree of intraepithelial neoplasia and type of tumour. ${ }^{*}$

\begin{tabular}{|c|c|c|c|c|c|c|c|}
\hline \multirow[t]{2}{*}{ (a) Gynaecological tissue } & & \multicolumn{6}{|c|}{ All receiving laboratories } \\
\hline & & $I N I, I I$ & IN III & $S q$ & Ad & Other & Total \\
\hline Originating laboratory's opinion & $\begin{array}{l}\text { IN I, II } \\
\text { IN III } \\
\text { Sq } \\
\text { Ad } \\
\text { Other } \\
\text { Total }\end{array}$ & $\begin{array}{l}0 \\
3 \\
0 \\
0 \\
0 \\
3\end{array}$ & $\begin{array}{r}0 \\
23 \\
0 \\
0 \\
0 \\
23\end{array}$ & $\begin{array}{r}0 \\
0 \\
21 \\
1 \\
0 \\
22\end{array}$ & $\begin{array}{r}0 \\
0 \\
0 \\
35 \\
2 \\
37\end{array}$ & $\begin{array}{l}0 \\
0 \\
1 \\
1 \\
1 \\
3\end{array}$ & $\begin{array}{r}0 \\
26 \\
22 \\
37 \\
3 \\
88\end{array}$ \\
\hline
\end{tabular}

(b) Respiratory tract tissue (excluding major categories of disagreement)

All receiving laboratories

\begin{tabular}{|c|c|c|c|c|c|c|}
\hline & & & & & & \\
\hline & & $S q$ & $A d$ & Oat & Other & Total \\
\hline 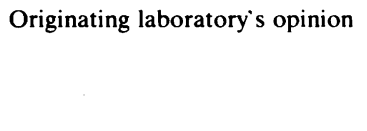 & $\begin{array}{l}\text { Sq } \\
\text { Ad } \\
\text { Oat } \\
\text { Other } \\
\text { Total }\end{array}$ & $\begin{array}{r}39 \\
0 \\
0 \\
4 \\
43\end{array}$ & $\begin{array}{r}3 \\
10 \\
2 \\
1 \\
16\end{array}$ & $\begin{array}{r}0 \\
0 \\
11 \\
3 \\
14\end{array}$ & $\begin{array}{r}6 \\
0 \\
2 \\
3 \\
11\end{array}$ & $\begin{array}{l}48 \\
10 \\
15 \\
11 \\
84\end{array}$ \\
\hline
\end{tabular}

${ }^{*}$ Excludes cases with disagreement in major categories and one case in which degree of intraepithelial neoplasia was not specified.

Table 6 Correlation between histology and cytology: all cytology reports (originating and receiving laboratories) compared with original histology reports. Degree of intraepithelial neoplasia and type of invasive tumour. ${ }^{*}$

(a) Cervical smears and gynaecological tissue

All cytology reports

\begin{tabular}{|c|c|c|c|c|c|c|c|}
\hline & & \\
\hline & & $I N I, I I$ & $I N I I I$ & $S q$ & Ad & Other & Total \\
\hline All original history reports & $\begin{array}{l}\text { IN I, II } \\
\text { IN III } \\
\text { Sq } \\
\text { Ad } \\
\text { Other } \\
\text { Total }\end{array}$ & $\begin{array}{l}0 \\
3 \\
0 \\
2 \\
0 \\
5\end{array}$ & $\begin{array}{r}0 \\
17 \\
1 \\
2 \\
0 \\
20\end{array}$ & $\begin{array}{r}0 \\
14 \\
23 \\
5 \\
0 \\
42\end{array}$ & $\begin{array}{r}0 \\
6 \\
2 \\
38 \\
4 \\
50\end{array}$ & $\begin{array}{l}0 \\
1 \\
2 \\
3 \\
1 \\
7\end{array}$ & $\begin{array}{r}0 \\
41 \\
28 \\
50 \\
5 \\
124\end{array}$ \\
\hline
\end{tabular}

(b) Sputum and respiratory tract tissue

All cytology reports

\begin{tabular}{|c|c|c|c|c|c|c|}
\hline & & & & & & \\
\hline & & $S q$ & Ad & Oat & Other & Total \\
\hline All original histology reports & $\begin{array}{l}\text { Sq } \\
\text { Ad } \\
\text { Oat } \\
\text { Other } \\
\text { Total }\end{array}$ & $\begin{array}{r}44 \\
3 \\
2 \\
7 \\
56\end{array}$ & $\begin{array}{r}8 \\
8 \\
5 \\
2 \\
23\end{array}$ & $\begin{array}{r}0 \\
0 \\
14 \\
3 \\
17\end{array}$ & $\begin{array}{r}7 \\
3 \\
3 \\
2 \\
15\end{array}$ & $\begin{array}{r}59 \\
14 \\
24 \\
14 \\
111\end{array}$ \\
\hline
\end{tabular}

${ }^{*}$ Excludes smears or tissue reported as benign or in which the degree of intraepithelial neoplasia was not specified.

almost complete absence of histological examinations of benign lesions. In this pilot study the small sample size adversely affects evaluation of the performance of individual laboratories. The figures given in lable 7, where sample sizes range from 29 to 56 , are of marginal validity, while the figures in Table 8 should be treated with even more reserve.

Kappa varies between +1 (perfect agreement) and negative values (indicating disagreement); with random agreement $\kappa=0$. The following qualitative assessments of agreement corresponding to different $\kappa$ values have been suggested by Landis and Koch ${ }^{12}$ :
+0.81 to +1 -almost perfect agreement

+0.61 to +0.8 - substantial agreement

+0.41 to +0.6 - moderate agreement

+0.21 to +0.4 -slight agreement

In addition, it is possible to segregate degree of disagreement into two categories:

$\mathrm{P}_{\mathrm{s}}=$ proportion of systematic disagreement (bias)

$\mathbf{P}_{\mathrm{h}}^{\mathrm{s}}=$ proportion of haphazard disagreement (due to lack of precise definition of categories).

It follows that if $\mathrm{P}_{0}=$ observed proportion of agreement:

$P_{s}+P_{h}=1-P_{o}$ 
Table 7 Cytology: agreement between individual receiving laboratories and originating laboratory's opinion. Major categories.

\begin{tabular}{|c|c|c|c|c|c|c|c|c|}
\hline Laboratory & $n$ & $P_{\mathrm{o}}$ & $P_{\mathrm{e}}$ & $\kappa$ & Seк & $\begin{array}{l}95 \% \\
\text { confidence }\end{array}$ & $\boldsymbol{P}_{\mathrm{s}}$ & $\boldsymbol{P}_{\mathbf{h}}$ \\
\hline $\begin{array}{c}\text { (a) Cervical } \\
\text { Z } \\
\text { Y } \\
\mathbf{X} \\
\mathbf{W} \\
\mathbf{V}\end{array}$ & $\begin{array}{c}\text { ars } \\
52 \\
32 \\
56 \\
56 \\
55\end{array}$ & $\begin{array}{l}0.92 \\
0.91 \\
0.89 \\
0.80 \\
0.85\end{array}$ & $\begin{array}{l}0.38 \\
0.39 \\
0.39 \\
0.34 \\
0.38\end{array}$ & $\begin{array}{l}+0.87 \\
+0.85 \\
+0.82 \\
+0.70 \\
+0.76\end{array}$ & $\begin{array}{l}0.06 \\
0.08 \\
0.07 \\
0.08 \\
0.08\end{array}$ & $\begin{array}{l}+0.75,+0.99 \\
+0.69,+1.01 \\
+0.68,+0.96 \\
+0.54,+0.86 \\
+0.60,+0.92\end{array}$ & $\begin{array}{l}0.04 \\
0.07 \\
0.11 \\
0.02 \\
0.02\end{array}$ & $\begin{array}{l}0.04 \\
0.02 \\
0.00 \\
0.18 \\
0.13\end{array}$ \\
\hline (b) Sputum & $\begin{array}{l}38 \\
29 \\
38 \\
39 \\
37\end{array}$ & $\begin{array}{l}0.87 \\
0.76 \\
0.84 \\
0.82 \\
0.84\end{array}$ & $\begin{array}{l}0.52 \\
0.52 \\
0.51 \\
0.51 \\
0.51\end{array}$ & $\begin{array}{l}+0.73 \\
+0.50 \\
+0.67 \\
+0.63 \\
+0.67\end{array}$ & $\begin{array}{l}0.11 \\
0.16 \\
0.12 \\
0.13 \\
0.12\end{array}$ & $\begin{array}{l}+0.52,+0.94 \\
+0.19,+0.81 \\
+0.44,+0.90 \\
+0.38,+0.88 \\
+0.44,+0.90\end{array}$ & $\begin{array}{l}0.03 \\
0.03 \\
0.05 \\
0.08 \\
0.05\end{array}$ & $\begin{array}{l}0.10 \\
0.21 \\
0 \cdot 11 \\
0 \cdot 10 \\
0 \cdot 11\end{array}$ \\
\hline
\end{tabular}

$\mathbf{n}=$ number of smears examined. For other abbreviations see Table 1.

Table 8 Cytology: agreement between individual receiving laboratories and originating laboratory's opinion. Degree of intraepithelial neoplasia and type of invasive cancer.

\begin{tabular}{|c|c|c|c|c|c|c|c|c|}
\hline Laboratory & $n$ & $P_{\mathrm{o}}$ & $P_{\mathrm{e}}$ & $\kappa$ & Seк & $\begin{array}{l}95 \% \\
\text { confidence }\end{array}$ & $P_{\mathrm{s}}$ & $P_{\mathrm{h}}$ \\
\hline $\begin{array}{l}\text { (a) Cervical } \\
\text { Z } \\
\text { Y } \\
\text { X } \\
\text { W } \\
\text { V }\end{array}$ & $\begin{array}{c}\text { ars } \\
32 \\
14 \\
30 \\
27 \\
27\end{array}$ & $\begin{array}{l}0.81 \\
0 \cdot 78 \\
0 \cdot 87 \\
0.81 \\
0.74\end{array}$ & $\begin{array}{l}0.29 \\
0 \cdot 27 \\
0.34 \\
0 \cdot 25 \\
0 \cdot 26\end{array}$ & $\begin{array}{l}+0.73 \\
+0.69 \\
+0.78 \\
+0.75 \\
+0.65\end{array}$ & $\begin{array}{l}0.07 \\
0.05 \\
0.09 \\
0.10 \\
0.11\end{array}$ & $\begin{array}{l}+0.60,+0.86 \\
+0.58,+0.80 \\
+0.60,+0.96 \\
+0.55,+0.95 \\
+0.43,+0.87\end{array}$ & $\begin{array}{l}0 \cdot 09 \\
0 \cdot 14 \\
0 \cdot 13 \\
0 \cdot 11 \\
0 \cdot 06\end{array}$ & $\begin{array}{l}0.10 \\
0.08 \\
0.01 \\
0.08 \\
0.13\end{array}$ \\
\hline $\begin{array}{l}\text { (b) Sputum } \\
\text { Z } \\
\text { Y } \\
\text { X } \\
\text { W } \\
\text { V }\end{array}$ & $\begin{array}{l}21 \\
14 \\
19 \\
20 \\
19\end{array}$ & $\begin{array}{l}0.62 \\
0.78 \\
0.74 \\
0.85 \\
0.63\end{array}$ & $\begin{array}{l}0 \cdot 27 \\
0 \cdot 32 \\
0 \cdot 34 \\
0 \cdot 33 \\
0 \cdot 26\end{array}$ & $\begin{array}{l}+0.48 \\
+0.68 \\
+0.61 \\
+0.78 \\
+0.50\end{array}$ & $\begin{array}{l}0 \cdot 14 \\
0 \cdot 16 \\
0 \cdot 15 \\
0 \cdot 12 \\
0 \cdot 15\end{array}$ & $\begin{array}{l}+0.21,+0.75 \\
+0.37,+0.99 \\
+0.32,+0.90 \\
+0.55,+1.01 \\
+0.21,+0.79\end{array}$ & $\begin{array}{l}0.19 \\
0.07 \\
0.05 \\
0.15 \\
0.21\end{array}$ & $\begin{array}{l}0.19 \\
0.15 \\
0.21 \\
0 \cdot 00 \\
0.16\end{array}$ \\
\hline
\end{tabular}

For abbreviations see Table 1 .

In Tables 7 and 8 , however, the number of cases in disagreement cells for individual laboratories is too small for $P_{s}$ and $P_{h}$ values to be reliable.

\section{Discussion}

Those responsible for laboratory proficiency have encouraged the development of external quality assessment schemes in all pathology disciplines, and some form of evaluation in cytopathology is also needed. From the present pilot study several points of interest emerge which could well influence future projects.

\section{REFERENCE POINT (CORRECT RESULT)}

With regard to the present cluster of laboratories Tables 1 and 4 show that, on the whole, the originating laboratory's opinion is a good reference point. There were some discrepancies: of the 120 smears circulated, 15 were considered unsuitable for reporting by one or more participants, and five smears reported as negative by the originating laboratory were considered to contain malignant or dyskaryotic cells by all four receiving laboratories. In the remaining cases the originating laboratory report was upheld by the consensus. This group of laboratories was self selected and highly motivated, and it will not always follow that the originating laboratory's opinion will usually be the right one in any given cluster. The consensus interpretation generally seems a more secure reference point, and five seems to be the minimum number in a cluster for a consensus to emerge clearly. Using the consensus interpretation as the reference point means delay in feedback to participating laboratories, however, and it was apparent in this study that delay reduced interest. A possible alternative is to use slides which have acquired a consensus interpretation from another cluster or from a panel of "experts." The disadvantage here is the potential bias in the influence on the source of material to be circulated (see below) and the fading of cytology smears as a result of multiple examinations.

In theory one would expect related histology 
reports, when available, to be superior as a reference point, but this study shows the problems which can arise. The first of these is that when the originating laboratory has given a negative cytology report it is a matter of chance if a tissue biopsy has been taken or if the patient came to necropsy. In fact, the quality of the histological report will depend on whether it was a small bite biopsy or examination of a large resected specimen, and this distinction may need to be made.

Cytological and histological correlation as shown in Tables 3 and 6 was disappointing as $\kappa$ values showed no more than moderate agreement. The slight agreement found between sputum cytology and respiratory tract tissue in Table $3 \mathrm{~b}$ may well be spurious because of the imbalance in categories. It is of particular interest to compare Table $6 \mathrm{~b}$, which shows areas of agreement and disagreement between sputum cytology and respiratory tract histopathology, with the similar table quoted by Silcocks ${ }^{11}$ from the work of Payne et al.$^{13}$ The superior degree of agreement achieved by Payne et al may be explained by uniformity of material produced by one laboratory, but could also be due to the fact that for convenience in our study we circulated at the most two smears and two sections for each case. Although it was intended that these should be diagnostic, it is possible that better correlation would have resulted if all material available for each case had been circulated.

In addition to discrepancies between histology and cytology reports due to dissimilarities of the type of material examined, there were administrative difficulties in organising the circulation of related histology sections in large departments where several histopathologists were involved. This was not a problem in the two laboratories in the cluster where the cytopathologist and the histopathologist were the same person. The conclusion reached from this study is that, at present, the consensus interpretation for cytology smears is the best reference point. This does not preclude the circulation of some related histological material as an educational exercise for both cytopathologists and histopathologists to enhance the beneficial effects expected from external quality assessment.

\section{SOURCE AND TYPE OF MATERIAL FOR ROUTINE} EXTERNAL QUALITY ASSESSMENT

Circulated material in this trial was contributed by all participants. This spread the burden of selection of suitable material but exaggerated the problem of variability in staining, which can be a matter of individual preference. It is also open to the introduction of controversial material by one or more laboratories (as happened in this study). Such behaviour can be identified, however, by the construction of tables (not shown) which reveal the proportion of disagreement of all receiving laboratories with each individual laboratory functioning as the originating laboratory. Selection of material by a single laboratory would be more controlled but could introduce bias as to the type of material selected. Another possibility would be to circulate material previously collected and bearing a consensus interpretation from a panel of "experts." Ideally, such smears would be validated by histological diagnoses also made by consensus. The obvious disadvantage of this approach is the tendency of stained material to fade after multiple examinations. Although this is overcome in teaching collections by restaining, the results might not be satisfactory for an external quality assessment study. A further objection might be the need for central control, which introduces an element of authoritarianism which many would find unacceptable.

The type of material circulated also has to be considered. It is not possible to reflect the pattern of the routine workload, with its large volume of negative smears. Not only would this be boring, but the length of time needed to evaluate the performance of individual laboratories would be unrealistic. The balance of half non-neoplastic smears and half neoplastic smears seems appropriate, but it would be an advantage from the point of view of statistical analysis of cytological and histological correlation if a search could be made to include "negative" smears which have incidentally been corroborated histologically.

Consideration also has to be given to the advantages and disadvantages of circulating a mixture of cytological specimens from different organ systems or concentrating on material from one system. The former has the advantage of reflecting routine practice, but again extends the time to collect enough reports to evaluate performance as each specimen type needs separate analysis. In any event not all laboratories handle all types of material cytologically or histologically, or both.

\section{TIME INVOLVED IN EXTERNAL QUALITY ASSESSMENT EXERCISES}

The time required to report four additional smears together with the time needed to select suitable material for circulation can be a considerable burden on a small laboratory, particularly if long and complicated proformas have to be completed as well.

There is also a time factor in the delay between reporting test smears and feedback of original and consensus reports. Even when meetings of the cluster can be held to review controversial material it is 
seldom possible for all members of participating laboratories to attend, and this reduces interest among junior members of staff. The method of overcoming this - evaluated in the present trialwas to circulate, in the sixth and last cycle, a sealed envelope containing the original cytology and histology reports and relevant sections together with the assessment smear. From the point of view of the participants this was highly successful but in a routine external quality assessment scheme could be criticised because of the risk of "cheating." With a responsible head of department holding the sealed envelope this seems unlikely, however, and an unusually high degree of agreement with original reports (especially if these proved out of consensus) should soon become apparent. A more acceptable variant would be to recycle test smears from one cycle, together with original reports and relevant sections, at the same time as the test smears of the next cycle.

\section{FUTURE OF EXTERNAL QUALITY ASSESSMENT SCHEMES IN CYTOPATHOLOGY}

Those responsible for laboratory performance are most interested in reducing major error-that is, that which adversely affects patient management. The use of kappa statistics provides a useful method of evaluating individual laboratory performance but needs a relatively large number of reports, preferably in a short period of time. Individual laboratories find difficulty in keeping up a circulation schedule when complicated proformas are used which demand detailed reporting of cell types present and prediction of the type of histological abnormality. When this is required reports tend to be held for the person holding ultimate responsibility and do not receive the routine treatment which it is the object of the exercise to assess. Reporting required of the participating laboratories should therefore be kept to a minimum in any realistic external quality assessment scheme.

The other element in quality assurance is educational; the object is to develop uniformity in the definition of cell categories and extrapolation to the prediction of tissue state. Unlike a simple assessment of basic laboratory competence this is time consuming and is perhaps better kept, for the present, as a separate educational exercise, possibly within the same cluster of laboratories. In the future, with increasingly widespread sophistication in cytopathology reporting, it might be possible to include this sort of analysis in external quality assessment schemes.

A simplified and improved modification of the present pilot study is suggested below.

1 Establish clusters of six laboratories, each originating 10 non-neoplastic and 10 neoplastic gynaecological smears from previous years for which tissue reports exist; this would be essential for neoplastic material. Each participant as a receiving laboratory would report on 100 smears and 50 sections, which makes calculations easier. A seventh non-participating laboratory would be needed to receive and analyse reports. Copies of all original cytology and histology reports would be sent to this non-participating laboratory.

2 Material (four smears weekly) would be circulated in five cycles as in the above scheme, but, in addition to comment on the acceptability of the preparation, the proforma would only require cells to be identified as: normal or reactive cells, predicting a benign lesion; dyskaryotic cells, predicting no more than intraepithelial neoplasia; cells that appear malignant or suspicious of malignancy, arousing serious suspicion of invasive cancer.

3 Test slides should not remain with the receiving laboratory for more than one week and should also be reported according to the custom of the laboratory, without receiving special attention. This would mean that in the absence of the head of the laboratory anything which would normally receive his attention would be reported by the usual deputy.

4 As soon as reports from receiving laboratories reached the coordinating laboratory the original cytology and (if available) histology reports would be supplied. This could be reinforced by recirculation of test smears and any related sections as part of the following cycle.

5 When the coordinating laboratory found that a consensus was developing in disagreement with the original report the originating laboratory would be asked to review all relevant material.

6 Given this routine, each laboratory would have reported 100 assessment smears in the course of 25 weeks and a six month summary could be provided by the coordinating laboratory which related results to the consensus interpretation.

7 This basic quality assessment could be combined with an educational exercise if arrangements were made for participants to meet in their clusters at regular intervals to discuss selected cases.

The cluster of participating laboratories included those of the first two authors; Dr Gordon Canti, then at St Bartholomew's Hospital, London; Dr David Melcher, Brighton General Hospital; and Dr Keith Randall, Orpington Hospital, Kent. We are immensely grateful to these cytopathologists for their cooperation throughout, for their helpful discussions before and during the study, and for allowing us to use their results. Thanks are also due to $\mathrm{Mr}$ MM Boddington for advice and for information 
about a related study which is being conducted in the south west of England. We are also grateful to Dr JC Macartney, St Thomas's Hospital, London, for bringing the applicability of kappa statistics to our notice and for checking the calculations and interpretation. The following histopathologists reported on tissue sections and their assistance is gratefully acknowledged: Dr CH Buckley, Dr Bernard Fox, Professor Harold Fox, Dr Nigel Harcourt-Webster, and the histopathologists of St Bartholomew's Hospital. We should like to acknowledge the assistance of $\mathrm{Mr}$ Ian Coulling at St Stephen's Hospital in the organisation of the exercise. The support of the Department of Health and Social Security, which enabled a series of working parties to meet during the preparation and conduct of the study, is much appreciated, as is the participation and wise advice given by members of the working parties.

\section{References}

' Whitehead TP, Woodford FP. External quality assessment of clinical laboratories in the United Kingdom. J Clin Pathol 1981;34:947-57.

${ }^{2}$ Husain OAN, Butler EB, Evans DMD, Macgregor JE, Yule R. Quality control in cervical cytology. J Clin Pathol 1974;27:933-44.

${ }^{3}$ Snell JJS, De Mello JV, Gardner PS. The United Kingdom national microbiology quality assessment scheme. J Clin Pathol 1982;35:82-93.
${ }^{4}$ Fleiss JL. Measuring nominal scale agreements among many raters Psychol Bull 1971;76:378-82.

${ }^{5}$ Fleiss JL, Nee JCM, Landis JR. Large sample variance of kappa in the case of different sets of raters. Psychol Bull 1979;86:974-7.

${ }^{6}$ Holman CDJ, James IR, Henan PJ, et al. An improved method of analysis of observer variation between pathologists. Histopathology 1982;6:581-9.

' Holman CDJ, Matz LR, Finlay-Jones LR, et al. Inter-observer variation in the histopathological reporting of Hodgkin's disease: an analysis of diagnostic sub-components using kappa statistics. Histopathology 1983; 7:399-407.

${ }^{8}$ Evans DMD, Shelley G, Cleary B, Baldwin Y. Observer variations and quality control of cytodiagnosis. J Clin Pathol 1974;27:945-50.

${ }^{9}$ Cocker J, Fox H, Langley FA. Consistency in the histological diagnosis of epithelial abnormalities of the cervix uteri. J Clin Pathol 1968;21:67-70.

${ }^{10}$ Thomas GDH, Dixon MF, Smeeton NC, Williams NS. Observer variation in the histological grading of rectal carcinoma.J Clin Pathol 1983;36:385-91.

" Silcocks PBS. Measuring repeatability and validity of histological diagnosis - a brief review and some practical examples.J Clin Pathol 1983;36:1269-75.

12 Landis JR, Koch GG. The measurement of observer agreement for categorial data. Biometrics 1977;33:159-74.

${ }^{13}$ Payne CR, Hadfield JW, Stavin PG, et al. Diagnostic accuracy of cytology and biopsy in primary bronchial carcinoma. J Clin Pathol 1981;34:773-8.

Requests for reprints to: Dr OAN Husain, Division of Pathology, St Stephen's Hospital, Chelsea, London SW10 9TH, England. 